УДК 621.78-97

\title{
АСИММЕТРИЧНЫЙ НАГРЕВ СТАЛИ В МЕТОДИЧЕСКИХ ПЕЧАХ ПРИ ГОРЯЧЕЙ ПРОКАТКЕ
}

\author{
Овчинников Михаил Александрович \\ студент \\ Научный руководитель: Горбунов Кирилл Сергеевич \\ преподаватель \\ ФГБОУ ВО «Липецкий государственный \\ технический университет»
}

Аннотация: При горячей прокатке температура является важнейшим фактором производства листа. В данной работе рассматривается нагрев металла в методической печи с помощью лабораторной муфельной печи МИМП-М и измерительных систем и архиваций показания температуры.

Ключевые слова: Сталь, образец, печь, нагрев, асимметрия, термопара.

\section{ASYMMETRIC HEATING OF STEEL IN METHODICAL FURNACES DURING HOT ROLLING}

\section{Ovchinnikov Mikhail Alekseevich Gorbunov Kirill Sergeevich}

\begin{abstract}
During hot rolling, temperature is the most important factor in sheet production. In this paper, the heating of metal in a methodical furnace with the help of a laboratory muffle furnace MIMP-M and measuring systems and archiving of temperature readings is considered.

Key words: Steel, sample, furnace, heating, asymmetry, thermocouple.

\section{Введение}

Нагрев металла - это процесс либо предшествующий обработке металла давлением, либо являющийся частью основного процесса термической обработки металла. Нагрев металла имеет важное значение, так как от его качества зависят качество конечной продукции и работа прокатного
\end{abstract}


оборудования. Нагрев металла проводят по определенной технологии, характер которой зависит от цели нагрева. [1]

Процесс нагрева металла сопровождается некоторыми нежелательными явлениями, из которых наиболее характерными являются его окисление (угар) и обезуглероживание. Необходимо отметить, что время нагрева, являющееся важным фактором технологии нагрева, определяет основные размеры рабочего пространства нагревательных печей. Нагрев стали в печах прокатных, кузнечных и некоторых термических цехов проводят в атмосфере продуктов сгорания топлива. При этом происходит взаимодействие окружающих нагреваемую сталь газов с железом, углеродом и легирующими элементами, которое приводит к окислению и обезуглероживанию ее поверхности. [2]

Вследствие окисления возникают невозвратимые потери металла, составляющие при каждом нагреве от $1-2$ (в термических печах). При этом увеличивается также трудоемкость последующей обработки изделий в связи с необходимостью удаления образовавшейся окалины. Повышенная твердость окалины вызывает более быстрый износ инструментов и увеличение брака при прокатке. Вследствие того что окалина по сравнению со сталью имеет меньшую теплопроводность, время нагрева металла в печах увеличивается, что приводит к снижению их производительности при прочих равных условиях; осыпающаяся окалина образует шлаковые наросты на поду печей и вызывает необходимость более частых ремонтов и повышенный расход огнеупорных материалов. [3-6]

\section{Оборудование}

Исследование проводилось в лаборатории кафедры ОМД ЛГТУ. Образцы нагревались в муфельной печи МИМП-М. Размер пространства печи составляет $105 \times 155 \times 200$ мм. Конструкция печи позволяет проводить нагрев образца без прямого воздействия теплового потока от нагревательных элементов. Загрузочное окно печи в период нагрева и охлаждения закрывались шамотным кирпичом, щели заделывались каолиновой ватой. Такой принцип изоляции позволит вывести термопары без подсуживания воздухом печного пространства (рисунок 1). 


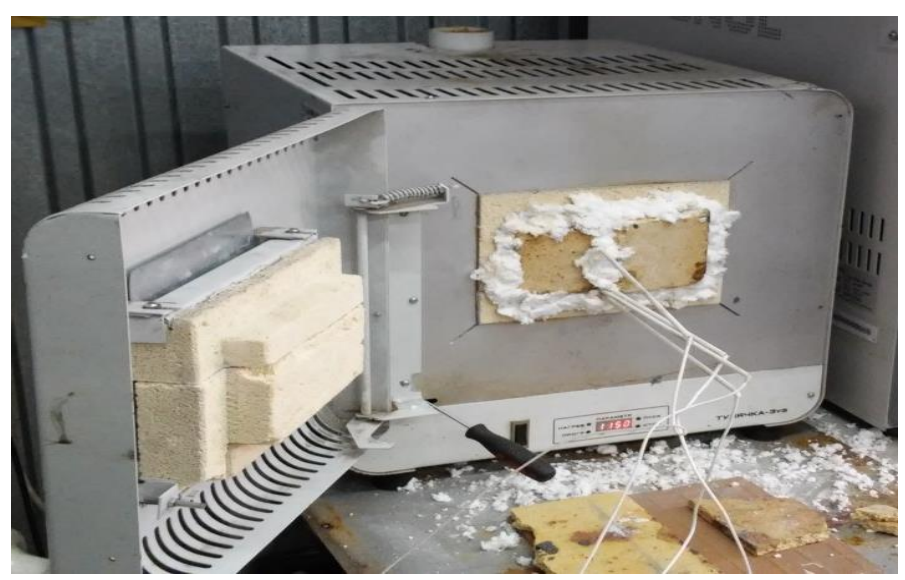

Рис. 1. Печь МИМП-М

Для измерения температуры металла по сечениям образца и температуры в печи использовали термопреобразователи термоэлектрические ДТПК031-0.5/0.45/1 производства ООО «Производственное объедение ОВЕН» (паспорт КУВФ.405220.004 ПС). Результаты изменения температуры в печи и в самом образце регистрировали с помощью 4-канального измерителя-регулятора с функцией архивирования ELHART ECD4-L (Рис.2).

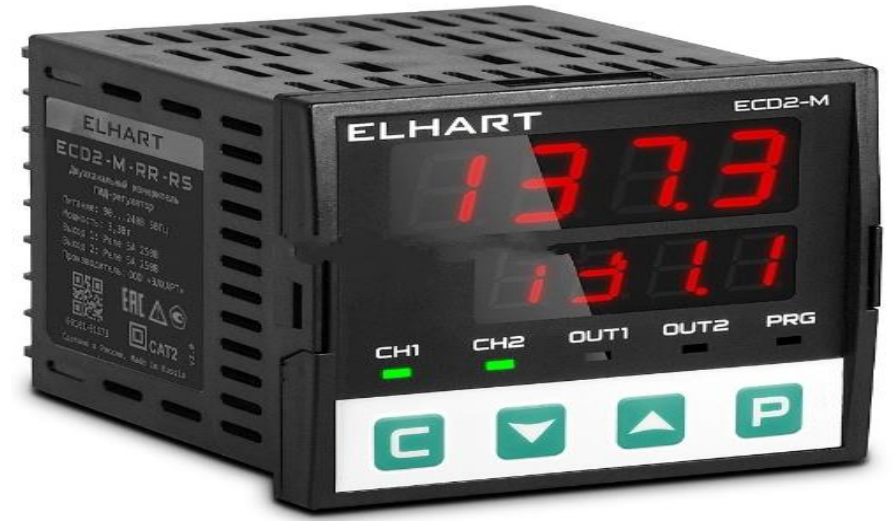

Puc. 2. ELHART ECD4-L

Термопреобразователи (далее по тексту-термопары) позволяет измерять температуру в диапазоне от $-40{ }^{\circ} \mathrm{C}$ до $1150{ }^{\circ} \mathrm{C}$. Две термопары зачеканивали в отверстия А и Б для обеспечивания контакта спая с металлом. Ещё две термопары использовались для измерения температуры печного пространства. Одна термопара располагалась сверху, а другая, снизу не касаясь подины. Спай термопар располагался на 2-3 мм над поверхностью образца около среднего отверстия Б. Термопары фиксировали хромоникелевой проволокой диаметром 0,5 мм. Длину термопар подбирали, таким образом, чтобы 
керамическая часть находилась в печи, а гибкая изоляция находилась снаружи печи и холодный спай находился на расстояний около 1,5 м от печи. Диаметр защитной арматуры 4,9 мм.

\section{Исследование}

Нагрев проводился ступенчато: первая ступень - 400/500 ${ }^{\circ} \mathrm{C}$, вторая $900{ }^{\circ} \mathrm{C}$, третья $-1150{ }^{\circ} \mathrm{C}$. Образец помещали в печь при температуре $400{ }^{\circ} \mathrm{C}$. На каждой ступени нагрева проводилась выдержка 30 минут. Прогрев определялся по показаниям средней и верхней термопар (Рисунок 3).

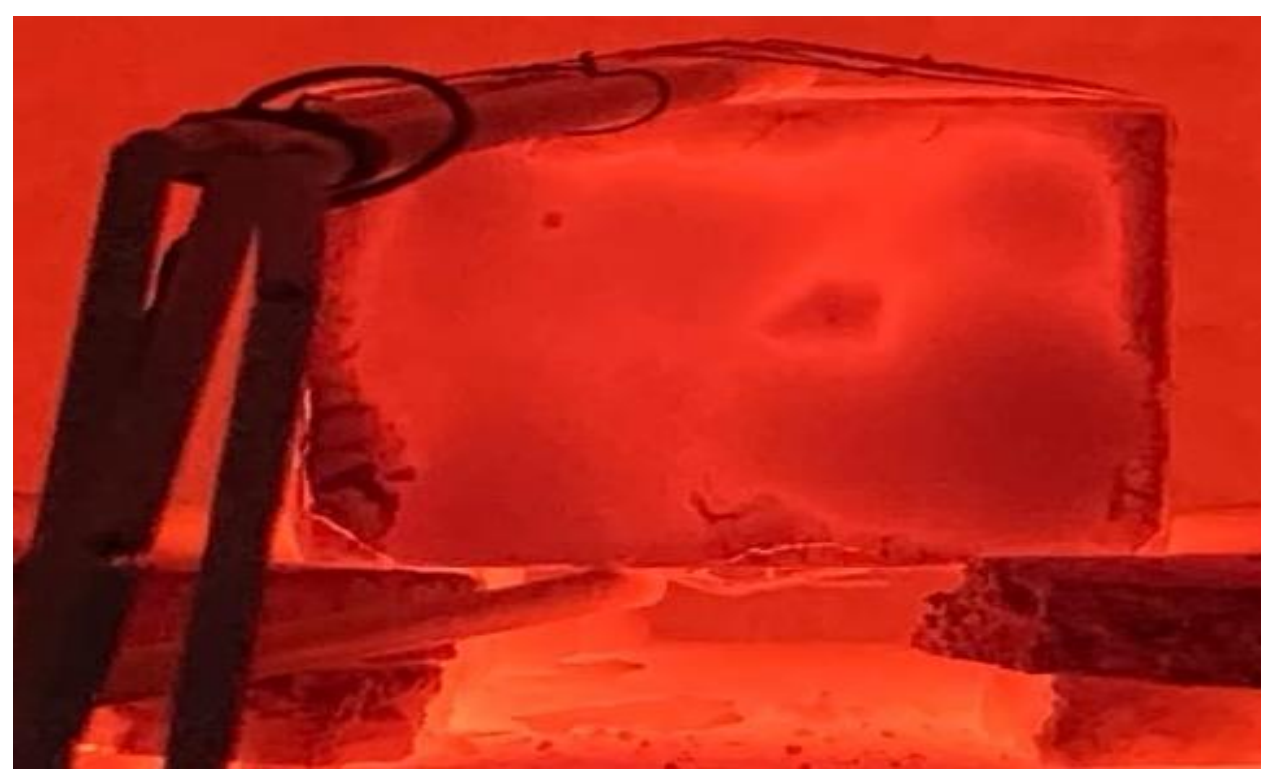

Рис. 3. Образец в печи

\section{Заключение}

В муфельной печи при исследовании нагрева образцов из стали марки $08 Ю$ и 17ГС (Рисунок 4,5). Было выявлено, что образцы нагревались несимметрично (асимметрично) по показанию нижней термопары. Таким образом, разница температур по высоте сляба увеличит усилие прокатки и воздействие на прокатную клеть. 


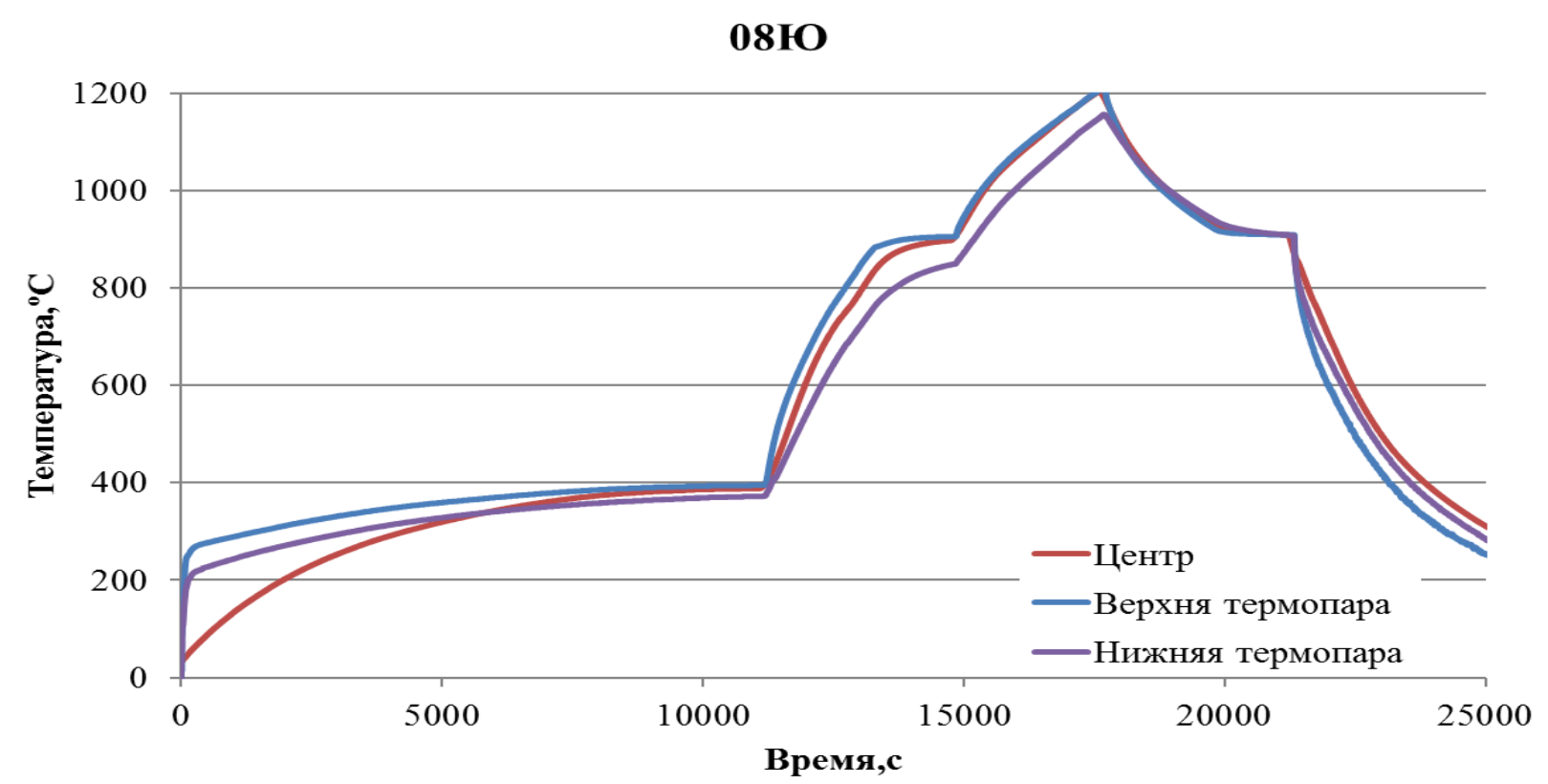

Рис. 4. Режим нагрева образца из стали марки $08 Ю$

17ГС

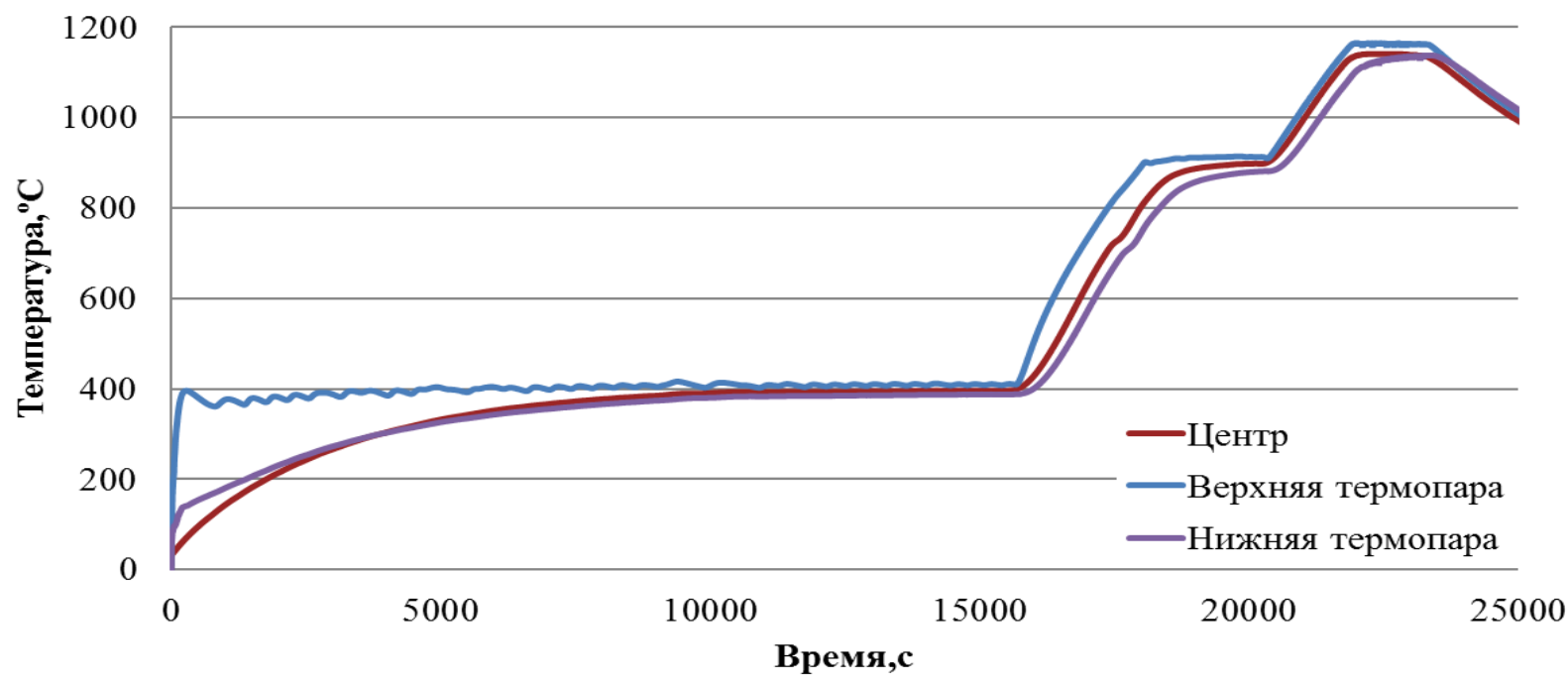

Рис. 5. Режим нагрева образца из стали марки 17ГС

\section{Список литературы}

1. Мордовкин Д. С. Исследование и оптимизация технологии нагрева непрерывно литых слябов в методических печах. ЛГТУ .: Металлургия, 2011. $-272 \mathrm{c}$

2. Соколов В.С., Ефремов А.В. Нагревательные печи и устройства - М.: Металлургия, 2010. - 231 с. 
3. Дождиков В.И., Чмырёв И.Н., Мордовкин Д.С. Анализ особенностей оптимальных режимов нагрева заготовок перед прокаткой. Бюллетень научнотехнической и экономической информации «Чёрная металлургия». 2008. - №10. - c. 55-61.

4. Соколов, А.К. О производительности нагревательных печей с минимальным расходом топлива Изв. вузов. Черная металлургия. -2014 . - № 3. - C. $43-48$.

5. Дождиков В.И., Воробьёв Р.А., Мордовкин Д.С. Идентификация параметров статической и динамической модели современных нагревательных печей. Современная металлургия начала нового тысячелетия: Сб. науч. тр., Часть 2. - Липецк: ЛГТУ, 2010 - с. 166-173.

6. Левыкина А.Г., Горбунов К.С., Позднякова А.И., Соловьев В.Н. Исследование теплового состояния металла с использованием методов физического и математического моделирования Вестник Магнитогорского государственного технического университета им. Г.И. Носова. 2021. Т.19. №3. C. $102-108$.

(C) К.С. Горбунов, М.А. Овчинников, 2021 